\title{
Ensino de Linguagem de Programação com Ênfase na Aprendizagem Significativa
}

\author{
Gilberto Astolfi' ${ }^{1}$, Dejahyr Lopes Junior ${ }^{1}$ \\ ${ }^{1}$ Instituto Federal de Educação, Ciência e Tecnologia de Mato Grosso do Sul. (IFMS) \\ Campus Campo Grande \\ 79.021-000 - Campo Grande - MS - Brasil \\ \{gilberto.astolfi, dejahyr.lopes\}@ifms.edu.br
}

\begin{abstract}
This paper describes an intervention, with emphasis on teaching practice, which prioritizes an educational approach led by the bias of meaningful learning in which the student develops the process of learning based on their previous knowledge. In the approach it is proposed to identify previous knowledge of the students, analyze them, minimize the conceptual deficiencies and finally introduce the new knowledge through the development of a software project throughout the course. The results presented suggest a constant reflection and resumption of the pedagogical practices and their implications, in which teachers and students share the central role of teaching and learning process.
\end{abstract}

Resumo. Este artigo relata uma intervenção, com ênfase na prática docente, que prioriza uma abordagem de ensino conduzida pelo viés da aprendizagem significativa, em que o estudante desenvolve o processo de aprendizagem tendo como base seu conhecimento prévio. Na abordagem é proposto identificar os conhecimentos prévios dos estudantes, analisá-los, amenizar as deficiencias conceituais e por fim introduzir o novo conhecimento por meio de desenvolvimento de um projeto de software ao longo da unidade curricular. Os resultados apresentados sugerem uma constante reflexão e retomadas das práticas pedagógicas e suas implicações, as quais professores e alunos compartilham o protagonismo do processo de ensino e aprendizagem.

\section{Introdução}

Aprender a partir daquilo que já sabemos de forma que o novo conhecimento tenha significado e se relacione com o conhecimento existente é a essência da teoria da Aprendizagem Significativa proposta por Ausebel (2003). Ensinar com o objetivo de favorecer tal aprendizagem não é uma tarefa simples, pois corresponde em proporcionar condições para que o estudante perceba e interprete o significado que the foi apresentado e, por meio da interação cognitiva desta nova idéia, com algum conhecimento prévio relevante que já possua, (re) organize sua estrutura cognitiva absorvendo assim o novo conhecimento [Mendonça 2012].

Os conhecimentos prévios de um estudante podem ter sido adquiridos em atividades cotidianas, na escola, no entretenimento, ou seja, em diversas condições e assuntos dos mais variados temas, formando assim a sua estrutura cognitiva. 
No contexto do ensino de linguagem de programação, principalmente nos últimos semestres de um curso, os conhecimentos prévios de um estudante são fomentados por disciplinas pré-requisitos de semestres anteriores. Em muitos casos, é percebido que os estudantes chegam com deficiências conceituais e despreparados para adquirir o novo conhecimento que lhe será transmitido.

Não identificar os conhecimentos prévios desses estudantes, principalmente as suas deficiências, e ensiná-los sem saber o que eles já conhecem, faz com que o docente pratique meramente o ensino mecânico ou repetitivo. Dessa forma, a aprendizagem pode não fazer sentido ao estudante e o novo conhecimento pode não se relacionar com o conhecimento existente em sua estrutura cognitiva. Nesse tipo de aprendizagem o novo conhecimento passa a ser armazenado isoladamente ou por meio de associações arbitrárias na estrutura cognitiva [Pelizzari et al 2002, Moreira 2012].

Nesse contexto o presente artigo propõe relatar uma intervenção que objetiva identificar os conhecimentos prévios e deficiências conceituais dos estudantes do sétimo semestre do Ensino Médio Integrado em Informática, no contexto da unidade curricular "Linguagem de Programação IV", a fim de orientá-los na construção de seus conhecimentos com base na teoria da aprendizagem significativa, ou seja, ensiná-los a partir daquilo que já sabem. Dessa forma, de acordo com Novak e Gowin (1999), os estudantes se tornam mais capazes de aprender a aprender, uma habilidade fundamental para o estudante de informática devido às constantes mudanças tecnológicas.

Nesse sentido, entendemos como objetivos deste artigo, contribuir para identificação de alguns pontos de dificuldade a serem superados no processo de ensino de linguagem de programação, bem como motivar a prática docente em iniciativas de ensino que possam fazer sentido no aprender do estudante.

O método utilizado na intervenção foi composto por três fases. Na primeira fase foi aplicada uma avaliação diagnóstica [Luckesi 2003] com o objetivo de identificar os conhecimentos prévios dos estudantes em relação ao tema "Linguagem de Programação de Computadores", como também suas deficiências conceituais. Na segunda fase, depois de uma análise do questionário aplicado na fase anterior por especialistas da área, foram preparados materiais compostos principalmente por vídeoaulas e postagens em blogs na internet, que consideramos serem organizadores prévios [Tavares 2010], com o objetivo de amenizar as deficiências conceituais dos estudantes em relação ao assunto que será ensinado, como também, ajustar os conhecimentos prévios dos estudantes para absorção do novo conhecimento. Finalmente, na terceira fase, os estudantes definiram seus projetos de softwares para serem desenvolvidos ao longo da unidade curricular.

\section{Aprendizagem Significativa}

Na concepção de Ausubel (2003), a aprendizagem significativa caracteriza-se pela interação entre um novo conhecimento e o conhecimento já existente na estrutura cognitiva do aprendiz de maneira substantiva (não literal) e não arbitrária, a um aspecto relevante da estrutura cognitiva do indivíduo. Nesse processo de aprendizagem, o conhecimento existente fica mais sólido, diferenciado e elaborado em termos de significados, adquirindo mais estabilidade e se internalizando por mais tempo [Moreira 2000]. 
Desse modo, os novos conhecimentos trabalhados pelo educador relacionam-se com o conhecimento que o estudante traz consigo; de experiências anteriores. Juntos eles formam uma estrutura de conhecimento que faz sentido ao estudante. Pode ser citado, como exemplo, a associação realizada pelo estudante, sobre conteúdos de diferentes disciplinas. Assim, um estudante que cursa linguagem de programação consegue relacionar o conteúdo de matrizes, conhecimento adquirido na disciplina de matemática, com vetores bidimensionais da informática, vislumbrando o potencial uso de matrizes matemáticas.

Tendo em vista o processo de aprendizagem, Ausubel (2003) afirma que só podemos aprender a partir daquilo que já conhecemos, destacando o conhecimento prévio como a variável mais importante no processo de aprendizagem. Assim, o aprendiz deve fazer uso do conhecimento internalizado, usando-o como âncora para absorção de novo conhecimento, tornando a aprendizagem progressiva, ou seja, os significados vão sendo captados e conectados e/ou fundidos progressivamente ao conhecimento já existente.

Cabe ao educador promover mecanismos para que o indivíduo consiga progressivamente diferenciar sua estrutura cognitiva, como também, reorganizar seus conhecimentos a fim relacioná-los. Dessa forma, é desejável que o novo conhecimento seja transmitido de maneira organizada e bem planejada, respeitando a sua estrutura hierárquica, além de procurar caminhar do mais genérico para o mais específico, sempre buscando estratégias para consolidação que seja atraente ao aluno.

Por outro lado, pouco se consegue se não houver condições para que a aprendizagem significativa ocorra. Ausubel (2003) afirma que para haver aprendizagem significativa são necessárias duas condições: primeira, o aprendiz precisa estar disposto a aprender. Se o aprendiz não estiver disposto a relacionar o novo conhecimento ao existente, optando por memorizá-lo, então a aprendizagem passa a ser mecânica. Isso mostra que o indivíduo não é só um receptor passivo e sim o protagonista no processo ensino-aprendizagem [Moreira 1980]; segunda, o novo conhecimento deve despertar o interesse do aprendiz, possuindo potencialmente significado, ou seja, o novo conhecimento deve ser lógico ao aprendiz e psicologicamente significativo.

\section{Metodologia}

A intervenção ocorreu em uma sala com 33 estudantes do sétimo semestre do Curso Técnico de Nível Médio Integrado em Informática do Instituto Federal de Educação, Ciência e Tecnologia de Mato Grosso do Sul, campus Campo Grande, na unidade curricular "Linguagem de Programação IV", ministrada por um dos pesquisadores. O período de intervenção foi de vinte semanas, sendo que as aulas ocorreram no período vespertino, totalizando 40 horas-aula de 45 minutos cada.

O conteúdo abordado foi o de Desenvolvimento Web utilizando a Linguagem de Programação Java. No planejamento da unidade curricular foi definido que o conteúdo seria abordado por meio de aulas objetivas, atividades práticas e pesquisa, objetivando que cada estudante tenha condições de desenvolver uma aplicação voltada para web utilizando a Linguagem de Programação Java. 
No início da unidade curricular o estudante deve definir um projeto de software a fim de resolver um problema real. Tal projeto é desenvolvido individualmente no decorrer de toda unidade. Espera-se com essa abordagem que o estudante tenha condições de aplicar os conceitos aprendidos de forma gradual, ou seja, à medida que o projeto é desenvolvido ao longo da unidade. Além disso, esperamos que resolvendo um problema cotidiano por meio de um projeto de software, o assunto a ser ensinado possa fazer sentido ao estudante e consequentemente despertar seu interesse, indo ao encontro das condições necessárias para que a aprendizagem significativa possa ocorrer.

Para tentar promover o princípio da aprendizagem significativa, ou seja, ensinar o estudante a partir daquilo que ele já sabe, optou-se por realizar uma avaliação diagnóstica a fim de levantar os conhecimentos prévios dos estudantes em relação ao tema que será ensinado. Esse mecanismo permite ao docente conhecer melhor seu grupo de alunos, ou seja, quais seus conhecimentos em relação ao tema e, principalmente, suas deficiências conceituais. Para atender os objetivos da unidade curricular, onde $o$ estudante deve ser capaz de desenvolver uma aplicação web utilizando Java, é necessário que o estudante tenha noção, principalmente, em relação ao tema comunicação entre cliente e servidor, design de páginas utilizando HTML e folhas de estilo.

Nesse sentido foram aplicadas 11 questões para cada estudante sobre o tema que eles deveriam possuir certo conhecimento para dar início à unidade curricular, das quais suas respostas foram avaliadas por dois especialistas da área de desenvolvimento de software web. As respostas foram categorizadas em: Satisfatória (o estudante possuía certo conhecimento prévio sobre o tema); Parcialmente Satisfatória (o estudante poderia ter vestígios de conhecimento prévio sobre o tema) e; Insatisfatória (o estudante não demonstra possuir conhecimento prévio sobre o tema).

Para ser realizada esta classificação, destacou-se o fato de que as respostas não necessariamente deveriam estar corretas em sua plenitude para que sejam consideradas Satisfatórias, mas sim, o estudante deveria demonstrar que possuía alguns conceitos sobre o conceito abordado nas questões. O especialista deveria identificar na resposta do estudante algum conhecimento que pudesse ser capaz de servir como âncora ou requisito para a absorção do novo conteúdo que seria ensinado. Vale ressaltar, que antes dos especialistas avaliarem as respostas, foi explanada a eles a teoria da Aprendizagem Significativa com enfoque principalmente no conceito de conhecimentos prévios.

Após análise das repostas foram preparados organizadores prévios, utilizando vídeoaulas e postagens em blogs da internet, para servirem de âncora para a absorção do novo conhecimento que seria ensinado, ou seja, foram introduzidos conteúdos sobre os conceitos que os estudantes não demonstraram conhecimento prévio aceitável para absorver o novo conhecimento.

Organizadores prévios são conceitos introdutórios, apresentados a fim de manipular a estrutura cognitiva dos estudantes, mediando e/ou interligando conceitos que o estudante sabe com o que ele pretende aprender [Ausebel 2003]. Assim, os organizadores prévios funcionam como conectores cognitivos, fornecendo um suporte para a incorporação e retenção sólida de novos conceitos, atuando como uma estratégia facilitadora para promoção da aprendizagem significativa [Tavares 2010]. 
Após a aplicação dos organizadores prévios, o mesmo questionário da avaliação diagnóstica foi submetido aos estudantes, e suas respostas foram avaliadas pelos mesmos dois especialistas, realizando comparações entre os primeiros resultados, a fim de verificar se houve avanço ou não em relação aos conhecimentos prévios dos estudantes.

Finalmente, após analisar os conhecimentos prévios dos estudantes e promover o reparo das possíveis arestas conceituais que possuíam, o conteúdo novo passou a ser ensinado de forma gradual, sendo que cada novo conceito ensinado deveria ser aplicado pelo estudante em seu projeto de software a fim de construí-lo de maneira incremental até conseguir resolver um problema do cotidiano.

\section{Análise dos dados da intervenção}

A análise se concentra nas três fases da intervenção, a avaliação diagnóstica, a aplicação dos organizadores prévios e na observação do aproveitamento dos estudantes, como também, na prática docente no decorrer da unidade curricular.

\subsection{Avaliação diagnóstica}

$\mathrm{Na}$ avaliação diagnóstica foram aplicadas questões abertas relacionadas ao tema Internet e Desenvolvimento Web, como apresentadas na Tabela 1.

Tabela 1. Questões utilizadas na avaliação diagnóstica

\begin{tabular}{|l|l|}
\cline { 2 - 3 } \multicolumn{1}{l|}{} & \multicolumn{1}{c|}{ Questões } \\
\hline Q1 & O que você entende por aplicação cliente-servidor? \\
\hline Q2 & Em uma aplicação cliente-servidor, como o cliente e servidor se comunicam? \\
\hline Q3 & O que é HTTP? \\
\hline Q4 & Quais são os métodos usados no HTTP? \\
\hline Q5 & O que você entende por páginas estáticas e páginas dinâmicas no contexto da web? \\
\hline Q6 & O que você entende por servidor de aplicação? \\
\hline Q7 & $\begin{array}{l}\text { Em uma aplicação cliente-servidor, como são transferidas as informações do cliente } \\
\text { para o servidor? }\end{array}$ \\
\hline Q8 & O que é HTML? \\
\hline Q9 & Para que você acha que é utilizado um formulário HTML? \\
\hline Q10 & $\begin{array}{l}\text { O que você entende por requisição e resposta no contexto de uma aplicação cliente- } \\
\text { servidor? }\end{array}$ \\
\hline Q11 & O que você entende por aplicação web? \\
\hline
\end{tabular}

O Gráfico na Figura 1 apresenta os resultados da avaliação diagnóstica. Os resultados de cada questão (Q1 a Q11) são apresentados em formato de percentagem, sendo as respostas classificadas como: Satisfatório (SA), Parcialmente Satisfatória (PS) e Insatisfatória (IN). No gráfico é apresentada a média simples da análise dos dois especialistas para cada questão. Por exemplo, o especialista 1 considerou que $65 \%$ das repostas da Q1 eram consideradas insatisfatórias (IN), já o especialista 2 considerou 67\% (IN), no cálculo da média simples consegui-se 66\% de respostas insatisfatórias (IN) para Q1. Esse critério foi aplicado para todas as questões para definir o percentual de AS, PA e IN para cada uma delas. 


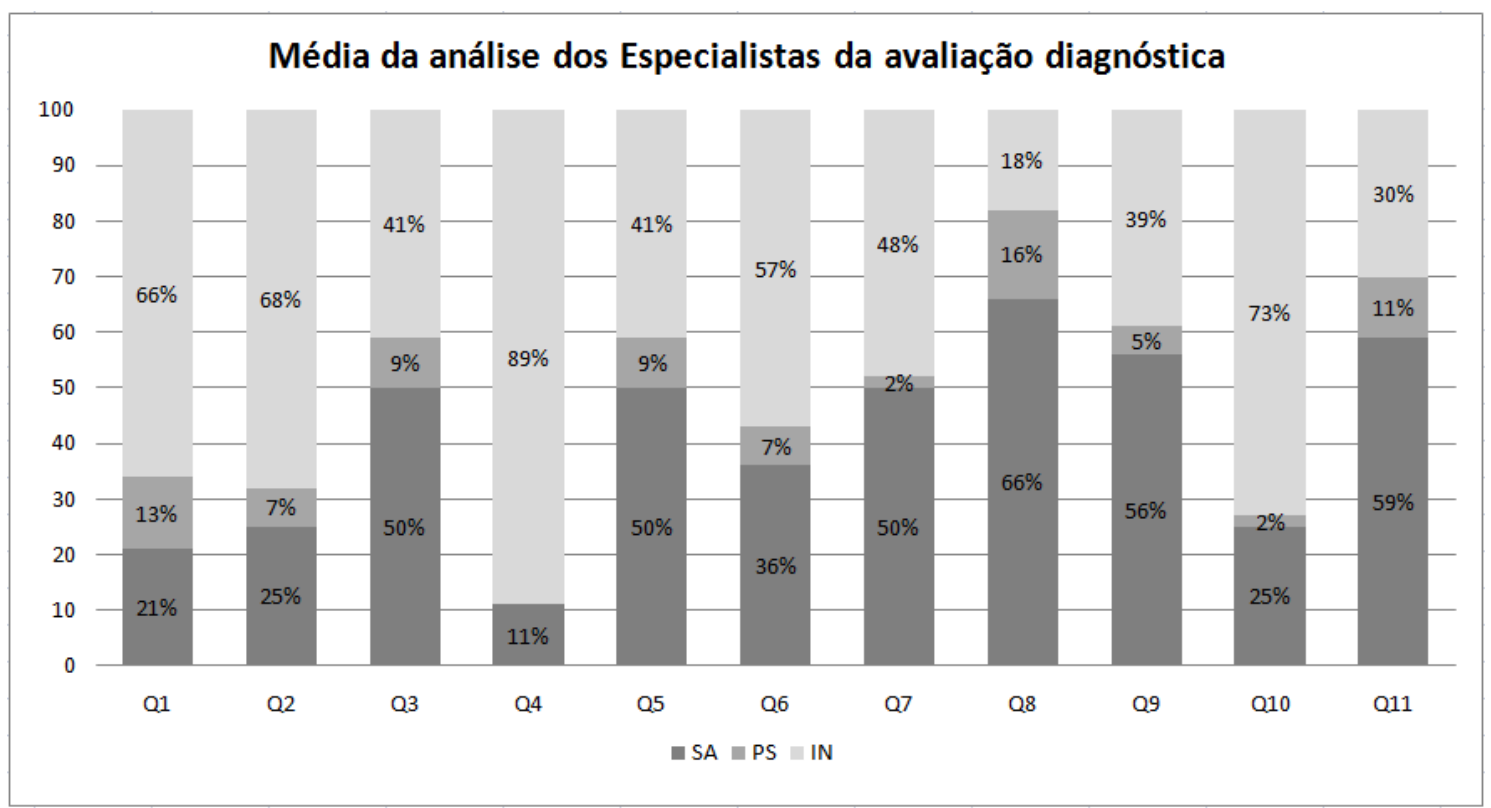

Figura 1. Resultado da análise da avaliação diagnóstica antes da introdução dos organizadores prévios.

Observou-se que os estudantes possuíam deficiências em relação ao conhecimento prévio indispensável para aprender o novo conteúdo em relação à temática. No resultado da questão Q4, por exemplo, que tinha como objetivo verificar se os estudantes possuíam conhecimento sobre "os métodos de comunicação entre um cliente e servidor", um conhecimento base para se entender como um cliente se comunica com um servidor, verificou-se que apenas $11 \%$ das respostas foram satisfatórias. Isso demonstra indícios de que o grupo de estudantes possuía pouco conhecimento prévio sobre o conteúdo.

Notou-se também em respostas às questões Q1, Q2, Q6 e Q10, que respectivamente objetivavam identificar se os estudantes possuíam conhecimentos prévios sobre "aplicações cliente-servidor", "comunicação entre cliente e servidor", "servidor de aplicação" e "requisição e resposta entre cliente e servidor", os resultados foram abaixo do desejável. Pois, esse tipo de conhecimento, mesmo que o estudante traga consigo de forma não consolidada, é imprescindível para o entendimento do conteúdo que seria ensinado.

As respostas às questões Q3, Q5, Q7, Q8, Q9 e Q11 atingiram um nível de satisfação (SA), em relação aos conhecimentos prévios exigidos para a compreensão do novo conteúdo, igual ou superior a 50\%. Este fato não pode ser considerado ótimo, uma vez que, nenhuma das questões aproximou-se de $100 \%$. Por outro lado, por se tratar de um conteúdo complexo, até mesmo para estudantes de graduação, os conhecimentos prévios observados dos estudantes para essas questões podem ser considerados razoáveis para a introdução do novo conteúdo.

\subsection{Aplicação dos organizadores prévios}

Os organizadores prévios, baseados em materiais expositivos (postagens em blogs da Internet e vídeoaulas), trataram principalmente de conceitos que os estudantes 
apresentaram maior dificuldade, observadas a partir da análise de suas repostas na avaliação diagnóstica.

Durante a exposição das vídeosaulas o docente sempre pausava e apresentava os conceitos de forma diferente, a fim de consolidar o conteúdo. Essa abordagem foi adotada, principalmente quando eram expostos os conceitos referentes às questões Q1, Q2, Q4, Q6 e Q10, onde foi percebido que os estudantes possuíam pouco conhecimento prévio sobre os conceitos necessários para o entendimento do novo conteúdo. O Gráfíco da Figura 2 apresenta os resultados após a análise da avaliação diagnóstica e introdução de organizadores prévios.

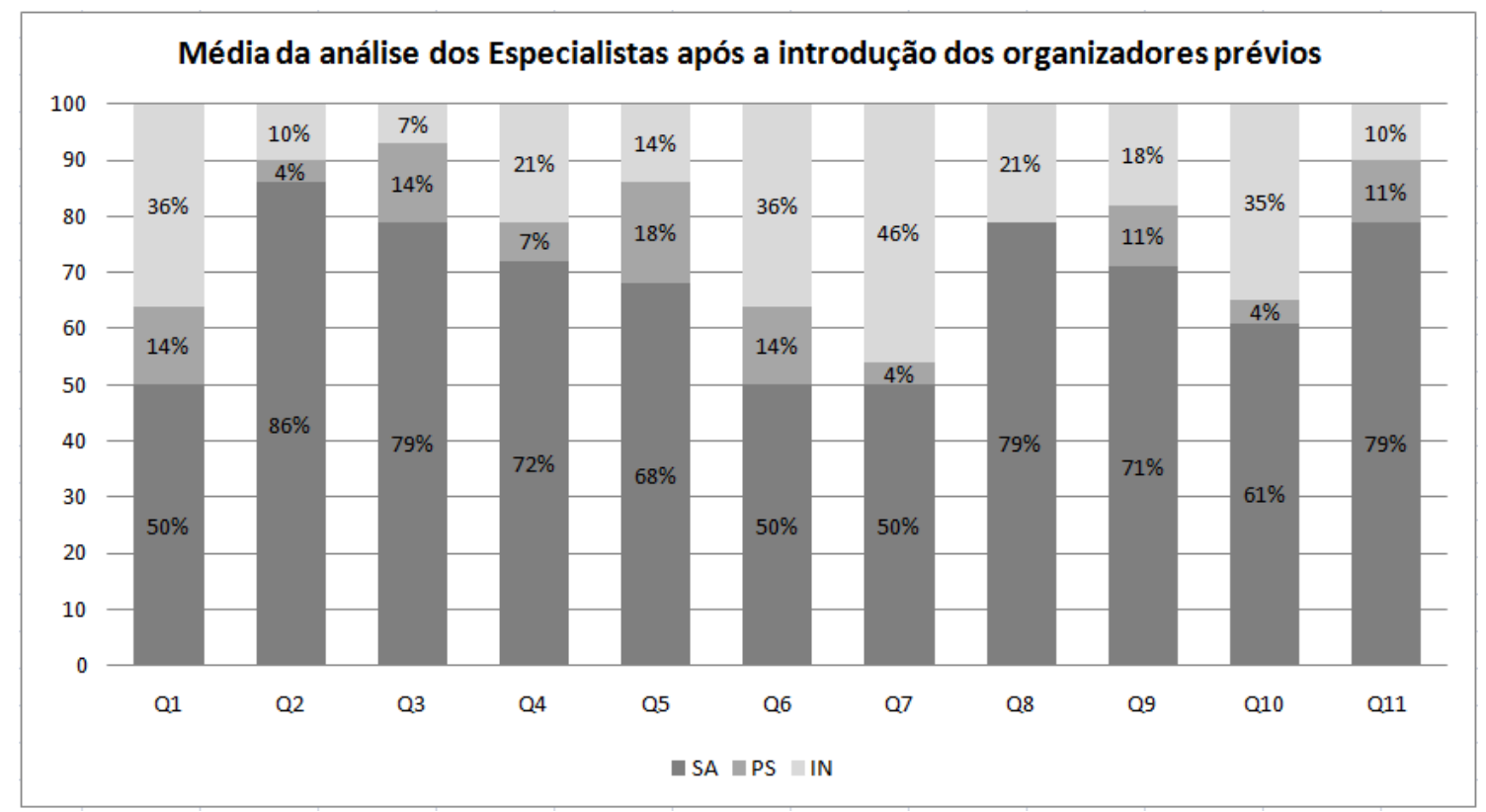

Figura 2. Resultado da análise das respostas dos estudantes após a introdução dos organizadores prévios.

As questões Q1, Q2, Q4, Q6 e Q10, após a introdução dos organizadores prévios, tiveram um avanço em relação à avaliação diagnóstica. Todas atingiram um nível de satisfação (SA) acima de 50\%. A questão Q4, que possuía o pior desempenho, obteve um avanço considerado satisfatório, não somente em números, mas na qualidade das repostas observada durante a análise textual. As demais questões Q1, Q2, Q6 e Q10 as repostas dos estudantes também demonstraram maior qualidade. Esse avanço demonstra que há indícios que houve um efeito satisfatório em relação à abordagem adotada pelo professor, que sempre pausava a exposição dos vídeos e reforçava a explicação dos conceitos.

As outras questões também demonstraram uma evolução quanto ao índice de satisfação (SA), como também na qualidade das repostas. Os dois Gráficos da Figura 3 mostram a evolução dos conhecimentos prévios dos estudantes na avaliação diagnóstica (Antes) e após a aplicação dos organizadores prévios (Depois). Os gráficos são baseados nas médias dos índices Satisfatório (SA), Parcialmente Satisfatória (PS) e Insatisfatória (IN). 


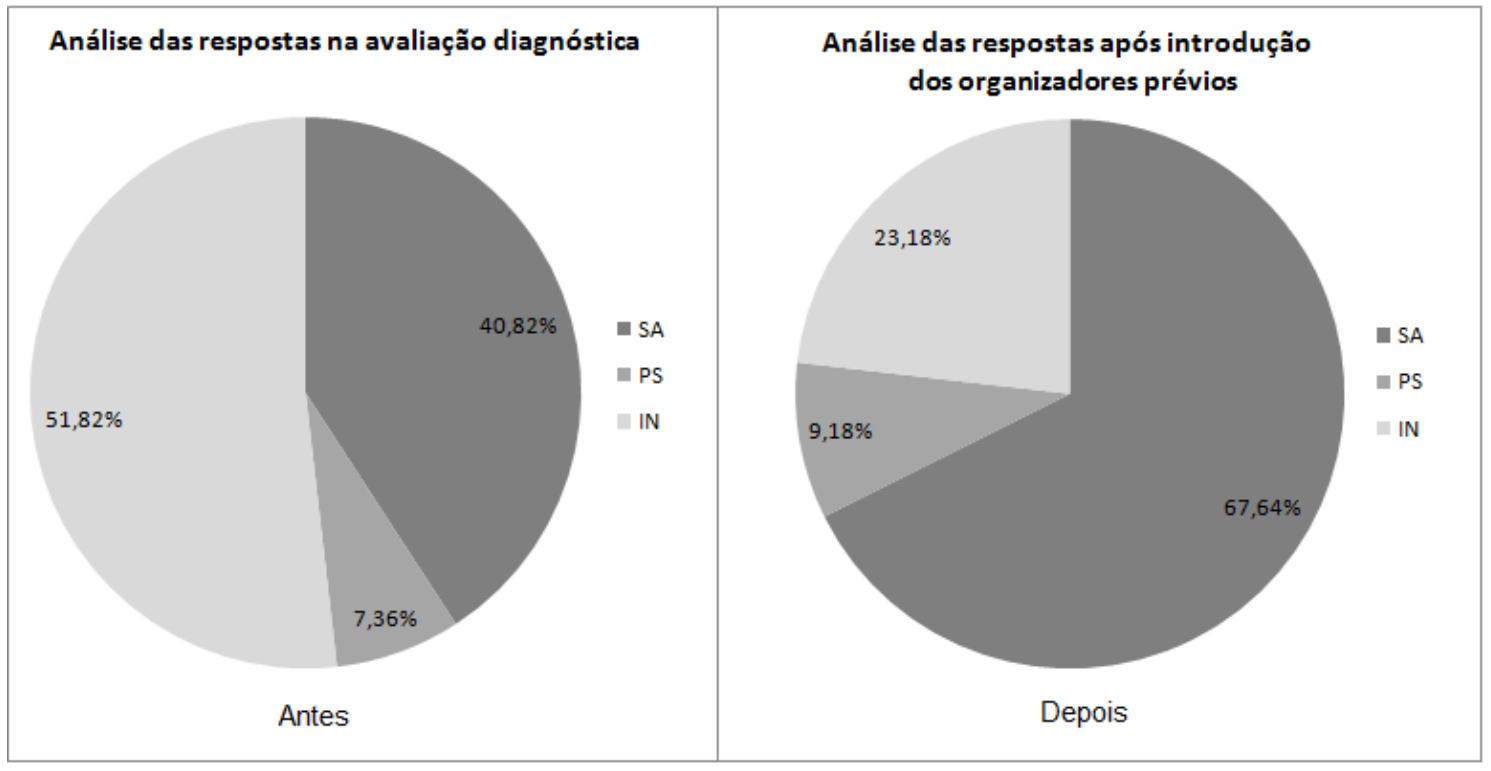

Figura 1. Resultado da análise das questões antes e após a introdução dos organizadores prévios.

Comparando os gráficos na Figura 3, observou-se que houve uma evolução em relação aos conhecimentos prévios dos estudantes necessários para receber o novo conhecimento. O que pode significar indícios de que a aplicação de organizadores prévios, a fim de aparar as arestas conceituais dos estudantes, apresentou resultados que, em certa medida, refletem um avanço do estado anterior de conhecimento.

Além disso, com os dados levantados sobre os conhecimentos dos estudantes, o docente poderá contemplar em sua prática pedagógica ações que estejam alinhadas com aquilo que os estudantes já sabem, promovendo assim a aprendizagem significativa, ou seja, o docente pode utilizar artifícios para que os estudantes consigam relacionar o novo conhecimento ao conhecimento prévio existente.

\subsection{Aproveitamento dos estudantes}

O desempenho individual de cada estudante foi analisado com base em sua média final na unidade. Para compor tal média, não foram aplicadas avaliações consideradas tradicionais, onde os estudantes respondem questões dissertativas ou escrevem trechos curtos de código para demonstrarem que aprenderam determinado conteúdo.

A avaliação da aprendizagem foi composta por três etapas durante o processo de desenvolvimento do projeto de software. Em cada etapa o estudante tinha que apresentar o projeto com as funcionalidades previamente definidas pelo docente. Por meio de uma entrevista o docente verificava se o estudante atingiu o objetivo daquela etapa, ou seja, se as funcionalidades estavam todas implementadas e se de fato foi o estudante que as fez. Para a segunda verificação o docente solicitava ao estudante que explicasse em detalhes como foi implementada uma determinada funcionalidade.

Para o estudante conseguir aprovação na unidade curricular sua média final deve ser superior ou igual a 7 e a frequência deve ser de no mínimo 75\%. As médias finais ficaram da seguinte forma: 
- $43 \%$ dos estudantes obtiveram notas entre 9 e 10 , esses estudantes conseguiram implementar o projeto de software integralmente, aplicando todos os conceitos aprendidos durante a unidade curricular.

- $24 \%$ obtiveram notas entre 8 e 9, alguns desses estudantes implementaram todo o projeto, mas durante as entrevistas eles não souberam responder algumas perguntas ao docente. Além disso, alguns estudantes, na primeira ou segunda etapa, não tinham implementado todas as funcionalidades definidas para aquela fase do projeto;

- $21 \%$ obtiveram entre 7 e 8 , esses estudantes não entregaram todas as funcionalidade definidas para seus respectivos projetos em cada etapa, como também, alguns não souberam responder perguntas feitas pelo docente durante as entrevistas.

- $\quad 9 \%$ de reprova, ou seja, nota final inferior a 7 e 3\% de desistência. Um fato observado entre esses estudantes é que todos tinham dependências de semestres anteriores e não concluiriam o curso naquele semestre.

\section{Análise e considerações finais}

Em um contexto onde se discute modelos tradicionais de educação, em que o ensino tipicamente é tratado de forma sequencial e segmentado, propor novos meios para ensinar a fim de despertar o interesse dos estudantes pode ser considerado um desafio. Conduzir o ensino por meio de projetos reais a serem desenvolvidos pelos próprios estudantes demonstrou ser uma alternativa para estimular um maior engajamento dos mesmos uma vez que conseguem atingir o objetivo da unidade curricular de uma maneira mais positiva. Dito de outro modo, fazendo algo que faça sentido a eles. Nessa perspectiva a aprendizagem pode ser considerada significativa ao estudante, visto que $o$ desenvolvimento de projetos de certa forma obriga-o a relacionar o seu conhecimento existente com o novo conhecimento a fim de construir algo palpável e percebível.

Para o docente, conhecer o que o estudante já sabe é importante, porque dá a oportunidade, durante a sua prática, de fazer relações mais seguras entre o conhecimento prévio do estudante com o novo conhecimento que será ensinado. Isso pode promover a consolidação do conhecimento prévio do estudante fazendo com que ele tenha sentido após a interação com o novo conhecimento.

O desenvolvimento de projetos ao longo da unidade curricular dá a oportunidade ao docente de avaliar a aprendizagem de forma não tradicional, como ocorreu durante a intervenção. Percebe-se que nessa abordagem, o estudante não demonstra tanta angustia e insegurança no momento de ser avaliado, pois ele está apresentando seu trabalho que foi realizado ao longo de algumas semanas. Isso pode evitar que o estudante aprenda mecanicamente com o objetivo de ser aprovado em um único teste. Por outro lado o estudante passa a ser estimulado a buscar novos conhecimentos fora do escopo da unidade curricular a fim de atingir seu objetivo.

Finalmente, acreditamos que o trabalho a partir de projetos resulte num constante movimento de reflexão e retomadas das práticas pedagógicas e suas implicações, onde professores e alunos compartilham o protagonismo do processo de ensino e aprendizagem de Linguagem de Programação e, principalmente, decidem por 
um trabalho fora de suas zonas de conforto, inaugurando assim um espaço diferenciado de aprendizagem dos conceitos aqui apresentados.

\section{Agradecimentos}

Nós agradecemos ao Instituto Federal de Educação, Ciência e Tecnologia de Mato Grosso do Sul (IFMS) pelo apoio financeiro recebido por meio do Edital $n^{\circ}$ 009/2015 PROPI/IFMS.

\section{Referências}

Ausubel, D. P. (2003). Aprender a aprender, Plátano Edições Técnicas, $1^{\text {a }}$ edição.

Luckesi, C. C. (2003). Avaliação da aprendizagem na escola: reelaborando conceitos e recriando a prática, Malabares Comunicação e Eventos.

Mendonça, C. A. S. (2012). Investigando conhecimentos dos licenciandos em biologia sobre aprendizagem significativa e mapas conceituais. In Aprendizagem Significativa em Revista, p.14-24.

Moreira, M. A. (1980). Mapas conceituais como instrumentos para promover a diferenciação conceitual progressiva e a reconciliação integrativa. Ciência e Cultura, p. 474-479.

Moreira, M. A. (2000). Aprendizagem significativa crítica. In: III Encontro Internacional sobre Aprendizagem Significativa, 2000, Peniche. Anais do III Encontro Internacional sobre Aprendizagem Significativa, 2000.

Moreira, M. A. (2012). Al final, que és aprendizaje significativo? Qurriculum (La Laguna), p. 29-56.

Novak, J. P. and Gowin, D. B. (1999). Aquisição e retenção de conhecimentos: uma perspectiva cognitiva, Plátano Edições Técnicas, $1^{\text {a }}$ edição.

Pelizzari, A., Kriegl, M. L., Baron, M. P., Finck, N. T. L. and Dorocinski, S. I. (2002). Teoria da Aprendizagem Significativa Segundo Ausubel. Revista do Programa de Educação Corporativa (PEC), p. 37-42.

Tavares, R. (2010). Aprendizagem significativa codificação dual e objetos de aprendizagem. Revista Brasileira de informática na Educação, p. 4-16. 